\title{
Anxiety and depression in old age: challenges in recognition and diagnosis
}

Recent years have seen much debate about both the prevalence and the nature of anxiety and depression in older adults. On the one hand, some authors have suggested that older populations are characterized by surprisingly high levels of wellbeing and resilience, despite increasing losses and functional impairment (Staudinger and Fleeson, 1996) and that the prevalence of mental illness, with the exception of dementia, decreases in late life (Jorm, 2000). Others have suggested that this is a spurious finding resulting from the methodological problems in obtaining accurate data for older adults (Beekman et al., 1998, Krasucki et al., 1999; O'Connor, 2006), with categorical diagnostic systems, such as the DSM-IV (American Psychiatric Association, 1994) and ICD-10 (World Health Organization, 1992) frequently cited as aggravating these difficulties (Palmer et al., 1997).

\section{The recognition of depression and anxiety}

This guest editorial focuses on the challenges in recognizing and diagnosing anxiety disorders and depression in older populations. Problematic though the DSM-IV criteria are, they are not the only challenge to the recognition and accurate diagnosis of these disorders in older adults. Some of the difficulty lies in issues that are unique to older people. First, older adults may be less likely to report symptoms of depression or anxiety. This is likely to be a cohort effect, rather than related to aging per se: it has been suggested that the current cohort of older adults may be less comfortable than later generations in discussing emotions, and they tend to take a somewhat stoic attitude to life's vicissitudes (Pachana, 2008). Secondly, it may be easier for older adults to avoid situations that evoke anxiety. For example, it may be more acceptable for an older adult who experiences a marked and persistent fear of social situations (Criterion A of the DSM-IV criteria for the diagnosis of Social Phobia) to avoid such occasions, as age-related stereotypes may reinforce the withdrawal of older people from social interaction. Such a person may, in fact, experience significant interference with

First published online 2 February 2010. social activities (Criterion $\mathrm{E}$ for the diagnosis of Social Phobia), but not come to clinical attention.

Thirdly, older people may also be less aware of the treatments available for anxiety or depression, particularly psychotherapeutic approaches (Woodward and Pachana, 2009). This problem is aggravated by the shortage of psychologists willing to work with this population (Lee et al., 2003). Furthermore, there is evidence that general practitioners (GPs - also known as primary care physicians) may be less likely to enquire about psychological symptoms than physical symptoms in their older patients (Collins et al., 1997). Finally, the language used by older adults may be different from that used by clinicians, with all these factors having the effect of reducing the recognition of depression and anxiety in older adults.

\section{Quantitative or qualitative differences in the presentation of anxiety and depression?}

Differences between younger and older adults in the presentation of depression are well documented, but there has been debate about whether these differences are quantitative or qualitative. Certainly, it does appear that older adults tend to experience symptoms too infrequently or in insufficient numbers to meet the DSM-IV (American Psychiatric Association, 1994) criteria for major depression. This has given rise to a number of terms to describe this type of "nonmajor" depression, such as "subsyndromal" (Flint, 2002), "subthreshold" (Judd and Akiskal, 2002) or "clinically significant non-major depression" (Lavretsky and Kumar, 2002). While these constructs have been useful in stimulating debate about depression that does not meet standard criteria (Jeste et al., 2005), they have also been criticized on a number of grounds. First, criteria for non-major depression are inconsistent: Judd and Akiskal (2002) defined subthreshold depression as having two or more simultaneous symptoms of depression present for most or all of the time for at least two weeks, while Lavretsky and Kumar (2002) stated that the term emerged to classify patients with fewer than five clinically significant symptoms.

Perhaps of greater importance is that terms such as "non-major" depression might suggest that 
this type of depression is not clinically important, which does not appear to be the case. A study by Chachamovich et al. (2008) assessed 4,316 respondents in 20 countries using the Geriatric Depression Scale (GDS; Yesavage et al., 1983) as a measure of depressive symptoms, and found that a GDS score as low as 2 was a predictor of lower quality of life and a more negative attitude toward aging. Moreover, depression was a stronger predictor of quality of life than other variables such as age, gender, marital status or educational level. Data from the Berlin Ageing Study have also confirmed the impact of what was termed "subthreshold depression" in old age on the ability to carry out activities of daily living (Wilms et al., 2000).

Turning to qualitative differences between depression in older and younger age groups, Blazer (2003) has suggested that a syndrome of "depression without sadness" may be more common in older adults. This is characterized by apathy and loss of interest, rather than subjectively experienced low mood. While not unique to older adults, it has been suggested that this presentation is more common in older than younger adults (Gallo et al., 1997). Another term used is "depletion syndrome", referring to a "depressionlike" syndrome experienced by older adults and characterized by a preponderance of physical symptoms and withdrawal (Newman et al., 1991).

Other unique features of the presentation of anxiety and depression in old age include the high level of comorbidity with physical illness and the well-documented difficulties that can arise in distinguishing psychological from physical symptoms (Koenig, 1998; Bryant et al., 2009). Comorbidity with cognitive impairment and dementia also complicate the picture. Finally, unlike depression in younger age groups, it appears that clear etiological factors can be identified, at least for a subgroup of geriatric depressions. It is generally accepted that a valid distinction on the basis of etiology can be made between early (generally defined as before the age of 60) and late onset depression (Conway and Steffens, 1999; Bagulho, 2002). Bagulho (2002) stated that the only well-replicated differences between early and late onset depression were indeed causative, with the underlying cause attributed to degenerative brain changes characterized by deep white matter hyperintensities and other vascular changes.

Thus, different lines of evidence converge to suggest that depression and anxiety are increasingly heterogeneous in old age, and are both experienced and expressed in ways that are different from their counterparts in younger populations. How then, do categorical diagnostic systems, such as ICD-10 and DSM-IV cope with these presentations that may be not only phenomenonologically but also etiologically diverse?

An answer to this question can be given by examining the current diagnostic criteria in DSMIV, using Generalized Anxiety Disorder (GAD) as an illustrative example. This disorder is defined as being worry that is deemed to be excessive (Criterion A), difficult to control (Criterion B), and is associated with three or more (one in children) physiological symptoms (Criterion C), and causes impairment in social, occupational or other areas of functioning (Criterion D) (italics mine). All of these criteria are potentially problematic in older adults. First, many older people deny that worries are excessive, saying, for example, that a fear of going out at night is justifiable in the context of visual impairment. The physiological symptoms listed under Criterion $\mathrm{C}$ include fatigue, tension and poor sleep, for which there could be health-related causes, while difficulty concentrating could be attributable to age- or dementia-related cognitive impairments. Finally, clinicians may be less inclined to pursue enquiries regarding the functional consequences of the symptoms, in light of the examples given in the manual ("social and occupational").

\section{Possible ways forward}

Even before work on DSM-V started formally in 2007, there was much discussion about the validity of the DSM-IV criteria for anxiety and depression in older adults, and as the pace of work on DSM$\mathrm{V}$ accelerates towards the anticipated publication date of 2012, there will certainly be an increased level of debate about this issue. One approach to the problems outlined is to improve the existing framework without making radical changes. Thus, a number of authors have called for criteria for the DSM criteria for anxiety (Beekman, 2008) or depression (Jeste et al., 2005) to be modified and made more sensitive to the needs of older patients.

Others have gone further and highlighted the inherent problems of a categorical system that imposes arbitrary boundaries to define case or non-case status (Flint, 2002). Beekman (2008) suggested that it may be more clinically useful, and consistent with empirical research, to lump disorders into broader categories, but split symptoms at a dimensional level. Flint (2002) has also advocated the use of a dimensional approach to the study of affective disorder in old age as this can "provide a framework for studying the complex interactions that exist between depression, anxiety, medical illness, cognitive impairment, personality and adverse psychosocial conditions" (Flint, 2002, p. 231). 
At the very least, a case can be made for making the text more age-friendly. Why, for example, are there currently two paragraphs of caveats with regard to the diagnosis of GAD in children, and no consideration of issues to guide clinicians in making accurate diagnoses in older adults? William Osler famously stated that "It is much more important to know what sort of a patient has a disease than what sort of a disease a patient has". We would do well to remember the importance of the "sort of patient" in relation to developing diagnostic criteria for anxiety and depression in older adults, so that these take into account the complexities of the presentation of these disorders in this age group.

\section{Conflict of interest declaration}

Christina Bryant is a member of the DSM-V Late Life Anxiety Disorders Advisory Group.

\section{CHRISTINA BRYANT}

Senior Lecturer in Clinical Psychology, School of Behavioural Science, University of Melbourne, Victoria, and Centre for Women's Mental Health, Royal Women's Hospital, Melbourne, Victoria, Australia

Email: cbryant@unimelb.edu.au

\section{References}

American Psychiatric Association (1994). Diagnostic and Statistical Manual of Mental Disorders, Fourth Edition. Washington, DC: American Psychiatric Association.

Bagulho, F. (2002). Depression in older people. Current Opinion in Psychiatry, 15, 417-422.

Beekman, A. (2008). Anxiety in aging: a newly chartered territory. American fournal of Geriatric Psychiatry, 16, 787-789.

Beekman, A. et al. (1998). Anxiety disorders in later life: a report from the Longitudinal Aging Study Amsterdam. International fournal of Geriatric Psychiatry, 13, 717-726.

Blazer, D. (2003). Depression in late life: Review and Commentary. Fournal of Gerontology: Medical Sciences, 58A, 249-265.

Bryant, C., Jackson, H. and Ames, D. (2009). Depression and anxiety in medically unwell older adults: prevalence and short-term course. International Psychogeriatrics, 21, 754-764.

Chachamovich, E., Fleck, M., Laidlaw, K. and Power, M. (2008). Impact of major depression and subsyndromal symptoms on quality of life and attitudes towards aging in an international sample of older adults. The Gerontologist, 48, 593-601.

Collins, E. et al. (1997). Management of depression in the elderly: referral for psychological treatments. British fournal of Clinical Psychology, 36, 445-448

Conway, C. and Steffens, D. (1999). Geriatric depression: further evidence for the "vascular depression" hypothesis. Current Opinion in Psychiatry, 12, 463-470
Flint, A. (2002). The complexity and challenge of non-major depression in late life. American Fournal of Geriatric Psychiatry, 10, 229-232.

Gallo, J., Rabins, P., Lyketsos, C., Tien, A. and Anthony, J. (1997). Depression without sadness: functional outcomes of nondysphoric depression in later life. fournal of the American Geriatric Society, 45, 570-578.

Jeste, D., Blazer, D. and First, M. (2005). Aging-related diagnostic variations: need for diagnostic criteria appropriate for elderly psychiatric patients. Biological Psychiatry, 58, 265-271.

Jorm, A. (2000). Does old age reduce the risk of anxiety and depression? A review of the literature. Psychological Medicine, 30, 11-22.

Judd, L. L. and Akiskal, H. S. (2002). The clinical and public health relevance of current research on sub-threshold depressive symptoms in elderly patients. American fournal of Geriatric Psychiatry, 10, 233-238.

Koenig, H. (1998). Depression in hospitalised older patients with congestive heart failure. General Hospital Psychiatry, 20, 29-43.

Krasucki, C., Howard, R. and Mann, A. (1999). Anxiety and its treatment in the elderly. International Psychogeriatrics, 11, 25-45.

Lavretsky, H. and Kumar, A. (2002). Clinically significant non-major depression: old concepts, new insights. American fournal of Geriatric Psychiatry, 10, 239-255.

Lee, K., Volans, P. and Gregory, N. (2003). Trainee clinical psychologists' views on recruitment to work with older people. Ageing and Society, 23, 83-97.

Newmann, J. P., Engel, R. J. and Jensen, J. E. (1991). Age differences in depressive symptom experiences. Fournal of Gerontology: Psychological Sciences, 46A, 224-235.

O'Connor, D. (2006). Do older Australians truly have low rates of anxiety and depression? A critique of the 1997 National Survey of Mental Health and Wellbeing. Australian and New Zealand Fournal of Psychiatry, 40, 623-631.

Pachana, N. (2008). Ageing and psychological disorders. In E. Rieger (ed.), Abnormal Psychology. Sydney: McGraw Hill.

Palmer, B., Jeste, D. and Sheikh, J. (1997). Anxiety disorders in the elderly: DSM-IV and other barriers to diagnosis and treatment. Fournal of Affective Disorders, 46, 183-190.

Staudinger, U. and Fleeson, W. (1996). Self and personality in old and very old age: a sample case of resilience? Development and Psychopathology, 8, 867-885.

World Health Organization (1992). Tenth Revision of the International Classification of Diseases and Related Health Problems (ICD-10). Geneva: WHO.

Wilms, H.-U., Kanowski, S. and Baltes, M. (2000). Limitations in ADLs: towards a better understanding of subthreshold mental disorders in old age. Comprehensive Psychiatry, 41, 19-25.

Woodward, R. and Pachana, N. (2009). Attitudes towards psychological treatment among older Australians. Australian Psychologist, 44, 86-93.

Yesavage, J., Brink, T., Rose, T., Lum, O., Huang, V., Adey, M. and Leirer, O. (1983). Development and validation of a geriatric depression scale: a preliminary report. Fournal of Psychiatric Research, 17, 37-49. 